\title{
Influence of posterior tibial slope on knee flexion in posterior stabilized fixed bearing primary total knee arthroplasty
}

\author{
Sandeep Kumar Kanugula, Mallesh Rathod*, Venugopal S. M., Mohan Babu Lebaku
}

\begin{abstract}
Department of Orthopedics, BIRRD (T) Hospital, Sri Padmavathi Medical College for Women, SVIMS, Tirupati, Andhra Pradesh, India
\end{abstract}

Received: 10 February 2020

Accepted: 26 February 2020

\author{
*Correspondence: \\ Dr. Mallesh Rathod, \\ E-mail: drmalleshrathod@gmail.com
}

Copyright: ( ) the author(s), publisher and licensee Medip Academy. This is an open-access article distributed under the terms of the Creative Commons Attribution Non-Commercial License, which permits unrestricted non-commercial use, distribution, and reproduction in any medium, provided the original work is properly cited.

\begin{abstract}
Background: The goal of total knee arthroplasty (TKA) is to relieve pain and maintain stable range of motion (ROM) for day to day activities. Among the various factors, posterior tibial slope slope (PTS) may play an important role in achieving good postoperative knee flexion. Our study aims to know the effectiveness of PTS on the ROM of the knee in a posterior cruciate ligament (PCL)-substituting TKA.

Methods: A total of 125 unilateral PCL-substituting TKA's were included in the study. Based on postoperative PTA which was measured on lateral radiograph, patients were divided into 3 groups, Group A (PTS of $\leq 2$ ) comprise of 24 patients. Group B consists of 91 patients (PTS of 3 to 7). Group C includes 10 patients (PTS of 8 or more). Functional outcome was measured by using knee society score (KSS) and Western Ontario and McMaster Universities osteoarthritis index (WOMAC) which were evaluated preoperatively and at 18months post operatively.

Results: Mean postop ROM was $92.91 \pm 10.632 ; 107.24 \pm 10.905 ; 107.49 \pm 13.944$ in group A, B, C respectively which was significantly related to mean postop PTS $(0.74 ; 5.62 ; 9.87$ in group A, B, C respectively) $(\mathrm{P}<0.05)$. Functional outcome was measured by KSS and WOMAC which showed no significant difference pre and postoperatively.

Conclusions: The results of our study validate the hypothesis that a positive correlation exists between the postoperative flexion and PTS in the PCL-substituting TKA, an increase in PTS can lead to a greater degree of the knee flexion for every extra degree of PTS.
\end{abstract}

Keywords: Total knee arthroplasty, Range of motion, Posterior tibial slope, PCL-substituting TKA

\section{INTRODUCTION}

The goal of total knee arthroplasty (TKA) is to relieve pain and maintain stable range of motion (ROM). TKA is a successful procedure for patients suffering from advanced arthritis. It helps to improve the ability to perform daily activities like standing, walking and climbing stairs which enhances patient satisfaction. ${ }^{1-3}$ Factors that influence ROM after TKA include Body mass index (BMI), preoperative ROM, intraoperative soft tissue balancing, posterior femoral condylar offset (PFCO), posterior tibial slope (PTS), implant design and physiotherapy. ${ }^{4-18}$ Among the various surgical factors PTS plays an important role in achieving good postoperative knee flexion. Patients with more PTS have the tendency to flex better than knees with little or no tibial slope. ${ }^{19,20}$ Our study aims to know the effectiveness of PTS on knee ROM in a posterior cruciate ligament (PCL)-substituting TKA.

\section{METHODS}

This is a prospective study that was carried out in BIRRD (T) Hospital, Tirupati, Andhra Pradesh, India between March 2018 to December 2019. Patients were followed up to 18 months. A total of 140 unilateral TKA's were operated during the study period. In all the patients DePuy 
PFC Sigma posterior stabilized prosthesis was implanted. Based on postoperative PTS which was measured on lateral radiograph of the knee, patients were divided into 3 groups. Group A (PTS of $\leq 2)$ comprise of 26 patients of which 2 patients were lost to follow up. Group B consists of 103 patients (PTS of 3 to 7) of which 12 patients were lost to follow up. Group C includes 11 patients (PTS of 8 or more) of which 1 patient were lost to follow up. At final follow up (18 months) a total of 125 patients were analysed.

\section{Inclusion criteria}

Patients with primary osteoarthritis. Patients age between 40 and 80 years. Minimum follow up of 18 months at the time of evaluation.

\section{Exclusion criteria}

Patients who underwent high tibial osteotomy, patients with posttraumatic and Inflammatory arthritis, revision total knee arthroplasty and patients who did not give consent for surgery were excluded.

TKA was performed by one of the four surgeons using DePuy PFC sigma posterior-stabilised fixed-bearing implants. After tourniquet inflated all knees exposed with standard medial parapatellar approach. Patella everted, partial fat pad excision done for better visualization of lateral tibial plateau. Proximal tibial cut with $3^{0}$ or $5^{0}$ PTS was performed perpendicular to tibial mechanical axis. Some surgeons preferred $3^{0}$ and the other $5^{0}$ PTS. Distal femoral cuts with $5^{0}$ valgus and posterior femoral cut was performed in $3^{0}$ external rotation with respective to posterior femoral condyles. Patelloplasty was done in all patients. Checked for patellar tracking, if patella maltracking occur then a lateral retinacular release is performed at least $2 \mathrm{~cm}$ lateral to the border of the patella. cementing of the femoral and tibial components was done. Wound closed in layers in $40-50^{\circ}$ of knee flexion over suction drain. Patient was mobilized on $1^{\text {st }}$ post op day. Radiographs of both weight bearing antero-posterior and lateral views were taken. The tibial slope was recorded as an angle between the line perpendicular to the tibial longitudinal axis and the line drawn along the superior margin of the proximal tibia or tibial base plate (Figure 1). ${ }^{16}$ Standard postoperative physiotherapy protocol was followed for every patient. Knee ROM measured in degrees by one degree increment goniometer. Functional outcome was measured by using knee society score (KSS) and Western Ontario and McMaster Universities osteoarthritis index (WOMAC) which were evaluated preoperatively and at 18 months postoperatively. ${ }^{21,22}$

\section{Statistical analysis}

Analysis was done using SPSS 21 software. Descriptive statistics (mean, standard deviation and proportions) were used to summarize the study variables. The $95 \%$ confidence intervals for difference of mean were used. The comparison between three groups regarding PTS, ROM and outcome of our study was done using ANOVA test was used, $\mathrm{p}<0.05$ was considered to be statistically significant.

\section{RESULTS}

During our study period a total of 140 patients were operated. Group A (PTS of $\leq 2$ ) comprise of 26 patients of which 2 patients were lost to follow up. Group B consists of 103 patients (PTS of 3 to 7) of which 12 patients were lost to follow up. Group $\mathrm{C}$ includes 11 patients (PTS of 8 or more) of which 1 patient were lost to follow up. At final follow up a total of 125 patients were analysed. Table 1 shows demographic data which had no significant difference among the groups ( $\mathrm{p}>0.05)$.

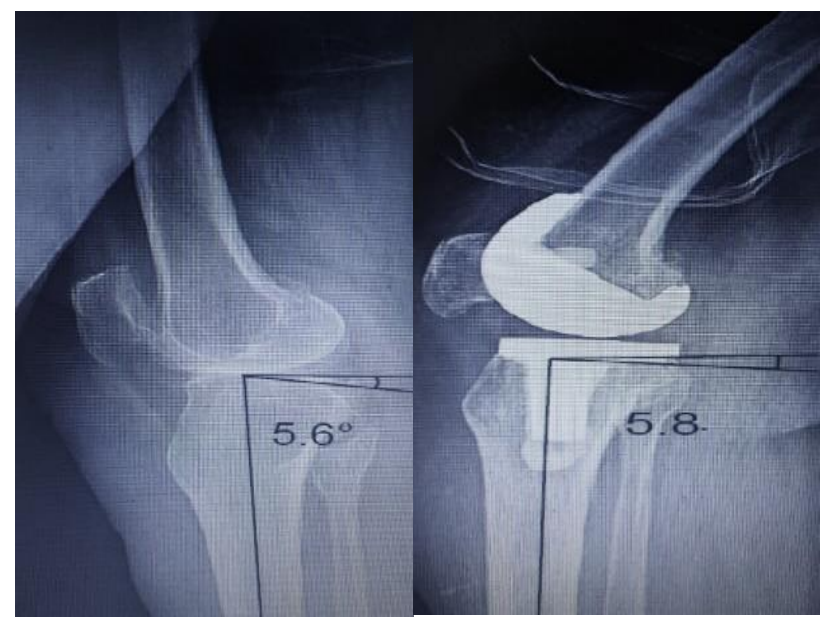

Figure 1: Preoperative and postoperative radiographs showing posterior tibial slope.

Table 1: Demographic data.

\begin{tabular}{|c|c|c|c|c|c|}
\hline \multirow{2}{*}{$\begin{array}{l}\text { Demographic } \\
\text { variables }\end{array}$} & \multicolumn{3}{|l|}{ PS } & \multirow{2}{*}{$\begin{array}{l}\text { F value } \\
\text { (p value) }\end{array}$} & \multirow{2}{*}{ Significance } \\
\hline & Group A & Group B & Group C & & \\
\hline Age & $62.38 \pm 7.966$ & $61.70 \pm 8.712$ & $65.80 \pm .957$ & $1.067(\mathrm{p}=0.347)$ & $\mathrm{P}>0.05$ \\
\hline $\begin{array}{l}\text { Gender } \\
\text { (male/female) }\end{array}$ & $17 / 7$ & $42 / 49$ & $5 / 5$ & $4.636(\mathrm{p}=0.098)$ & $\mathrm{P}>0.05$ \\
\hline BMI & $26.66 \pm 1814$ & $27.41 \pm 2.661$ & $27.56 \pm 3.269$ & $0.885(0.415)$ & $\mathrm{P}>0.05$ \\
\hline
\end{tabular}


Table 2: WOMAC and KSS in both groups.

\begin{tabular}{|c|c|c|c|c|c|}
\hline \multirow{2}{*}{ Mean values } & \multicolumn{3}{|l|}{ PS } & \multirow{2}{*}{ F value (p value) } & \multirow{2}{*}{ Significance } \\
\hline & Group A $(n=24)$ & Group B (n=91) & Group C $(n=10)$ & & \\
\hline Pre op WOMAC & $66.90 \pm 5.840$ & $71.03 \pm 8.349$ & $68.29 \pm 6.388$ & $2.928(0.057)$ & $\mathrm{P}>0.05$ \\
\hline Post op WOMAC & $30.58 \pm 3.944$ & $29.60 \pm 5.168$ & $29.87 \pm 4.153$ & $0.321(0.726)$ & $\mathrm{P}>0.05$ \\
\hline Pre op KSS & $26.90 \pm 10.64$ & $27.38 \pm 9.577$ & $27.00 \pm 9.953$ & $0.015(0.985)$ & $\mathrm{P}>0.05$ \\
\hline Post op KSS & $158.90 \pm 17.23$ & $168.50 \pm 12.353$ & $165.24 \pm 11.55$ & $2.199(0.115)$ & $\mathrm{P}>0.05$ \\
\hline
\end{tabular}

Table 3: Posterior tibial slope (PTS) and range of motion (ROM).

\begin{tabular}{|c|c|c|c|c|c|}
\hline \multirow{2}{*}{ Mean values } & \multicolumn{3}{|l|}{ PS } & \multirow{2}{*}{ F value (p value) } & \multirow{2}{*}{ Significance } \\
\hline & Group A $(n=24)$ & Group B (n=91) & Group C (n=10) & & \\
\hline Pre op PTS & 9.67 & 8.74 & 9.12 & $2.958(0.055)$ & $\mathrm{P}>0.05$ \\
\hline Pre ROM & $87.0 \pm 17.512$ & $88.7 \pm 10.347$ & $87.91 \pm 11.597$ & $0.1944(0.824)$ & $\mathrm{P}>0.05$ \\
\hline
\end{tabular}

Table 4: Posterior tibial slope (PTS) and range of motion (ROM).

\begin{tabular}{|c|c|c|c|c|c|}
\hline \multirow{2}{*}{ Mean values } & \multicolumn{3}{|l|}{ PS } & \multirow{2}{*}{ F value (p value) } & \multirow{2}{*}{ Significance } \\
\hline & Group A $(n=24)$ & Group B (n=91) & Group C $(n=10)$ & & \\
\hline Post op PTS & 0.74 & 5.62 & 9.87 & $3.553(0.032)$ & $* \mathrm{P}<0.05$ \\
\hline Post ROM & $92.91 \pm 10.632$ & $107.24 \pm 10.905$ & $107.49 \pm 13.944$ & $16.187(0.0001)$ & $* * \mathrm{P}<0.001$ \\
\hline
\end{tabular}

* Significant; **Highly Significant.

Functional outcome was measured by KSS and WOMAC which had shown no significant difference pre and postoperatively (Table 2). Mean pre-operative PTS was 9.67; 8.74; 9.12 in group A, B, C respectively. Mean preoperative ROM was $87.05 \pm 17.512 ; 88.75 \pm 10.347 ; 87.91 \pm$ 11.597 in group A, B, C respectively. Both pre-operative PTS and pre-operative ROM had no statistically significant difference between the groups $(\mathrm{p}>0.05)$ (Table 3). Mean post-operative ROM was 92.91 \pm 10.632 ; $107.24 \pm 10.905 ; 107.49 \pm 13.944$ in group A, B, C respectively which was significantly related to mean postoperative PTS $(0.74 ; 5.62 ; 9.87$ in group A, B, C respectively) $(\mathrm{p}<0.05)$.

\section{DISCUSSION}

TKA is one of the most successful surgical procedure with over $90 \%$ survival rate at $10-15$ year. ${ }^{23-26}$ ROM after TKA is essential factor for patient satisfaction. There are many factors which influence postoperative ROM among which PTS plays an important role in achieving good postoperative knee flexion. ${ }^{19,20}$ Patients with more PTS have the tendency to flex better than knees with little or no PTS but most published clinical studies have failed to show an effect of tibial slope on maximal flexion. ${ }^{27-30}$ Kansara et al concluded that there was no significant difference in the postoperative ROM between the knees with $0^{0}$ and $5^{\circ}$ of PTS after PCL-sacrificing TKA. ${ }^{16,17}$ Bauer et al reported that the correlation between PTS and maximal knee flexion that was observed after PCLretaining TKA was not noted after PCL-sacrificing TKA. ${ }^{15}$ Walker et al, in a computer modelling study, studied the effects of a $10^{\circ}$ posterior tilt, neutral tilt, and a $10^{\circ}$ anterior tilt and were compared. They concluded that a $10^{0}$ posterior tilt produced no less than $30^{\circ}$ of additional flexion when compared with the neutral tilt and anterior tilt had the opposite effect. ${ }^{20}$ Bellemans et al reported that an increase in $1^{0}$ PTS leads to mean increase of knee flexion by $1.7^{0}$ after PCL-retaining TKA based on evaluation of knees with $0^{0}, 4^{0}$, and $7^{0}$ PTS. ${ }^{2}$ Malviya et al observed that an increase of $1^{0}$ of PTS had increased the flexion angle by an average of $2.3^{\circ}$ in 101 knees after PCLretaining TKA. $^{31} \mathrm{Kim}$ et al observed statistically significant positive correlation between PTS and maximal flexion angle after PCL-sacrificing TKA using a medial pivot implant. They also stated that, understanding the design characteristics of the PCL-sacrificing medial pivot knee system that has a larger contact area in the medial compartment compared to the PCL-substituting knee implants could contribute to the correlation between PTS and flexion range. ${ }^{3}$ Catani et al. found a significant correlation between the tibial slope and flexion in an in vivo video-fluoroscopic study on the knee kinematics of the PCL-substituting TKA implants. ${ }^{32}$ Shi et al stated that the PTS is positively correlated with the postoperative maximal knee flexion ( $\mathrm{r}=0.681)$. Increasing the tibial slope by $1^{0}$ in the posterior-stabilized TKA can increase the maximal knee flexion by an average of $1.8^{0}$. In addition, if the flexion and extension gap are symmetrical and well balanced during the surgery, the tibial slope does not affect the joint stability even though the posterior slope exceeds $10^{0} .{ }^{33}$ In our study flexion angle of the knee after PCL-substituting TKA was correlated with PTS. There was improvement in postoperative ROM in all the patients. Postoperative ROM was more in the group with higher PTS ( $p<0.001)$. Therefore, we conclude that PTS is one of the surgeons factor that influences flexion angle after PCLsubstituting TKA. Limitations in our study are cases operated by multiple surgeons, the lack of comparison with other implants, the possibility of error in 
measurement of the maximal flexion angle, intraoperative factors like soft tissue balancing were not considered.

\section{CONCLUSION}

The results of our study validate the hypothesis that a positive correlation exists between the post-operative flexion and the PTS in the PCL-substituting TKA, an increase in PTS can lead to a greater degree of the knee flexion for every extra degree of PTS.

Funding: No funding sources

Conflict of interest: None declared

Ethical approval: The study was approved by the institutional ethics committee

\section{REFERENCES}

1. Cross WW, Saleh KJ, Wilt TJ, Kane RL. Agreement about indications for total knee arthroplasty. Clin Orthop Relat Res. 2006;446:34-9.

2. Bellemans J, Robijns F, Duerinckx J, Banks S, Vandenneucker H. The influence of tibial slope on maximal flexion after total knee arthroplasty. Knee Surg Sports Traumatol Arthrosc. 2005;13:193-6.

3. Kim JH. Effect of posterior femoral condylar offset and posterior tibial slope on maximal flexion angle of the knee in posterior cruciate ligament sacrificing total knee arthroplasty. Knee Surg Relat Res. 2013;25:54-9.

4. Dennis DA, Komistek RD, Scuderi GR, Zingde S. Factors affecting flexion after total knee arthroplasty. Clin Orthop Relat Res. 2007;464:53-60.

5. Higuchi H, Hatayama K, Shimizu M, Kobayashi A, Kobayashi T, Takagishi K. Relationship between joint gap difference and range of motion in total knee arthroplasty: a prospective randomised study between different platforms. Int Orthop. 2009;33:997-1000.

6. Kotani A, Yonekura A, Bourne RB. Factors influencing range of motion after contemporary total knee arthroplasty. J Arthroplasty. 2005;20:850-6.

7. Kurosaka M, Yoshiya S, Mizuno K, Yamamoto T. Maximizing flexion after total knee arthroplasty: the need and the pitfalls. J Arthroplasty. 2002;17(4):5962.

8. Ritter MA, Berend ME, Harty LD, Davis KE, Meding JB, Keating EM. Predicting range of motion after revision total knee arthroplasty: clustering and log-linear regression analyses. J Arthroplasty. 2004;19:338-43.

9. Bin SI, Nam TS. Early results of high-flex total knee arthroplasty: comparison study at 1 year after surgery. Knee Surg Sports Traumatol Arthrosc. 2007;15:350-5.

10. Bellemans J, Banks S, Victor J, Vandenneucker H, Moemans A. Fluoroscopic analysis of the kinematics of deep flexion in total knee arthroplasty. Influence of posterior condylar offset. J Bone Joint Surg Br. 2002;84:50-3.
11. Goldstein WM, Raab DJ, Gleason TF, Branson JJ, Berland K. Why posterior cruciate-retaining and substituting total knee replacements have similar ranges of motion: the importance of posterior condylar offset and cleanout of posterior condylar space. J Bone Joint Surg Am. 2006;88(4):182-8.

12. Hanratty BM, Thompson NW, Wilson RK, Beverland DE. The influence of posterior condylar offset on knee flexion after total knee replacement using a cruciate-sacrificing mobile-bearing implant. J Bone Joint Surg Br. 2007;89:915-8.

13. Massin P, Gournay A. Optimization of the posterior condylar offset, tibial slope, and condylar roll-back in total knee arthroplasty. J Arthroplasty. 2006;21:889-96.

14. Wyss T, Schuster AJ, Christen B, Wehrli U. Tension controlled ligament balanced total knee arthroplasty: 5-year results of a soft tissue orientated surgical technique. Arch Orthop Trauma Surg. 2008;128:12935.

15. Bauer T, Biau D, Colmar M, Poux X, Hardy P, Jacob LA. Influence of posterior condylar offset on knee flexion after cruciate-sacrificing mobile-bearing total knee replacement: a prospective analysis of 410 consecutive cases. Knee. 2010;17:375-80.

16. Kansara D, Markel DC. The effect of posterior tibial slope on range of motion after total knee arthroplasty. J Arthroplasty. 2006;21:809-13.

17. Piazza SJ, Delp SL, Stulberg SD, Stern SH. Posterior tilting of the tibial component decreases femoral rollback in posterior-substituting knee replacement: a computer simulation study. J Orthop Res. 1998;16:264-70.

18. Ranawat CS. Design may be counterproductive for optimizing flexion after TKR. Clin Orthop Relat Res. 2003;(416):174-6.

19. Walker P. Requirements for successful total knee replacements. Design considerations. Orthop Clin North Am. 1989;20:15-29.

20. Walker PS, Garg A. Range of motion in total knee arthroplasty. A computer analysis. Clin Orthop. 1991;262:227.

21. Insall JN, Dorr LD, Scott RD, Scott WN. Rationale of the Knee Society clinical rating system. Clin Orthop. 1989;248:13-14.

22. Roorda LD, Jones CA, Waltz M. Satisfactory crosscultural equivalence of the Dutch WOMAC in patients with hip osteoarthritis waiting for arthroplasty. Ann Rheum Dis. 2004;63:36-42.

23. Ranawat CS, Padgett DE, Ohashi Y. Total knee arthroplasty for patients younger than 55 years. Clin Orthop Relat Res. 1989;248:27-33.

24. Rand JA, Trounsdale RT, Ilstrup DM. Factors affecting the durability of primary total knee prostheses. J Bone Joint Surg Am. 2003;85(2):25965.

25. Scuderi GR, Insall JN, Windsor RE. Survivorship of cemented knee replacements. J Bone Joint Surg Br. 1989;71(5):798-803. 
26. Gioe TJ, Killeen KK, Grimm K. Why are total knee replacements revised. Analysis of early revision in a community knee implant registry. Clin Orthop Relat Res. 2004;428:100-06.

27. Akagi M, Ueo T, Matsusue $\mathrm{Y}$, Akiyama $\mathrm{H}$, Nakamura T. Improved range of flexion after total knee arthroplasty. Bull Hosp Jt Dis. 1997;56:225-32.

28. Kim J, Sang MM. Squatting following total knee arthroplasty. Clin Orthop. 1994;313:177-86.

29. Migaud H, Ladoucette DA, Dohin B, Cloutier J, Gougeon F, Duquennoy A. Influence of the tibial slope on tibial translation and mobility of nonconstrained total knee prosthesis. Rev Chir Orthop Reparatrice Appar Mot. 1996;82:7-13.

30. Schurman D, Parker J, Ornstein D. Total condylar knee replacement. A study of factors influencing range of motion as late as two years after arthroplasty. J Bone Joint Surg Am. 1985;67:100614.

31. Malviya A, Lingard EA, Weir DJ, Deehan DJ. Predicting range of movement after knee replacement: the importance of posterior condylar offset and tibial slope. Knee Surg Sports Traumatol Arthrosc. 2009; 17:491-8.

32. Catani F, Fantozzi S, Ensini A, Leardini A, Moschella D, Giannini S. Influence of tibial component posterior slope on in vivo knee kinematics in fixed-bearing total knee arthroplasty. J Orthop Res. 2006;24:581-7.

33. Shi X, Shen B, Kang P, Yang J, Zhou Z, Pei F. The effect of posterior tibial slope on knee flexion in posterior-stabilized total knee arthroplasty. Knee Surg Sports Traumatol Arthrosc. 2013;21(12):2696703.

Cite this article as: Kanugula SK, Rathod M, Venugopal SM, Lebaku MB. Influence of posterior tibial slope on knee flexion in posterior stabilized fixed bearing primary total knee arthroplasty. Int J Res Orthop 2020;6:487-91. 